\title{
Direito, Estado e Telecomunicações: fronteiras institucionais regulatórias (Apresentação)
}

Law, State and Telecommunications: institutional regulatory borders (Presentation)

\begin{abstract}
RESUMO
O presente estudo figura como introdução à Revista de Direito, Estado $e$ Telecomunicações do Grupo de Estudos em Direito das Telecomunicações da Universidade de Brasília, abordando sinteticamente a estrutura, conteúdo e política editorial da revista. Em acréscimo, o texto analisa os principais acontecimentos do setor no Brasil, bem como normas e julgados relativos ao ano de 2012, para registro das principais discussões político-jurídicas do setor de telecomunicações brasileiro referentes ao ano anterior ao da publicação.
\end{abstract}

\section{ABSTRACT}

This article introduces the current issue of the Law, State, and Telecommunications Review by way of presenting its structure, contents, and editorial policy. Statutes and regulations issued in 2012 and pertaining to telecommunications are referred to in detail. It also addresses the main discussions that framed the political and legal landscape of the Brazilian telecommunications sector in the year before the publication of this volume.

\section{Apresentação}

Em consonância com o propósito inaugural da Revista de Direito, Estado e Telecomunicações, apresenta-se o quinto volume da publicação segundo o formato que se segue, mantendo-se a perspectiva de consolidação da revista como um instrumento de pesquisa jurídica setorial.

Para tanto, a presente apresentação vai além da identificação das temáticas constantes da publicação e dá sequência ao registro histórico do arcabouço normativo setorial e do correspondente contexto socioeconômico e político das telecomunicações no Brasil. $\mathrm{O}$ artigo introdutório também registra as principais discussões jurídico-regulatórias que marcaram o ano de 2012. 
Este volume da Revista de Direito, Estado e Telecomunicações é inaugurada com a temática que provavelmente mais tem ocupado a agenda política brasileira, ainda no primeiro semestre de 2013, referente à discussão federativa de competências fiscalizatórias e normativas sobre estações rádiobase celulares - as antenas de cobertura do Serviço Móvel Pessoal. Em um formato claro e dirigido ao grande público, Alexandre Veronese implementa uma análise jurisprudencial do estado da arte brasileiro sobre cobrança pelo uso do solo por leis ou decretos municipais e de embargos administrativos de autorização para instalação de infraestrutura ou sua remoção. Os conflitos judiciais sobre regulação de telecomunicações, entretanto, não resumem o escopo do artigo, que busca determinar o perfil dos atores partícipes da discussão pública sobre a instalação das antenas de celulares no Brasil, concluindo pela notável ausência da sociedade civil em discussões pautadas por autoridades públicas de distintos níveis e espaços federativos.

Em sequência, a análise da natureza jurídica das telecomunicações aeronáuticas em meio ao processo recente de desestatização da infraestrutura de navegação aérea brasileira vem descrita por Fernando Feitosa no estudo intitulado "Telecomunicações Aeronáuticas: natureza jurídica, regime regulatório e formas de delegação", que lança novas luzes sobre o complexo sistema regulatório partilhado para dita categoria de serviços de telecomunicações.

Segue-se o estudo de Simone Scholze intitulado "A retomada dos esforços de P\&D nas telecomunicações brasileiras: uma perspectiva das teorias regulatórias", que aborda o papel da agência reguladora brasileira de telecomunicações no incentivo a atividades de pesquisa e desenvolvimento do setor, tendo por enfoque o referencial de Robert Horwitz em sua proposta de uma teoria geral da regulação. $O$ artigo fornece um conjunto de elementos da ordem jurídico-institucional e da dimensão teórico-regulatória relevantes para o estudo das razões e legitimidade do exercício da regulação por incentivos por parte da ANATEL para promoção de atividades de pesquisa e desenvolvimento nacional.

$\mathrm{O}$ artigo intitulado "A independência real das agências reguladoras no Brasil”, de Paulo Soares Sampaio, implementa uma revisão de literatura nacional e internacional sobre as características identificadoras das agências reguladoras para concluir pela necessária ponderação de circunstâncias institucionais, políticas e jurídicas para efetiva independência das agências Revista de Direito, Estado e Telecomunicações, v. 5, n. 1, p. 1-28 (2013)

DOI: https://doi.org/10.26512/1str.v5i1.21561 
reguladoras. A importação verificada no modelo de agências reguladoras brasileiro, mediante reprodução da organização de garantias da legislação estadunidense não reflete, segundo o autor, as particularidades do quadro legal/normativo, social e político brasileiro, gerando, com isso, uma "tendência de crescimento da influência do Poder Executivo e de redução do poder e da independência real das agências reguladoras em seus aspectos de autonomia estrutural, de autonomia econômico-financeira e autonomia funcional".

Em sintonia com o momento histórico brasileiro de discussão do marco civil da internet, o livro "Consent of the Networked: The Wordlwide Struggle for Internet Fredom", de autoria de Rebecca Mackinnon, publicado em 2012, encontra-se resenhado por Elaine Cristina Xiol y Ferreira, afirmando a importância da superação da postura hobbesiana de um contrato social da internet obediente aos soberanos digitais californianos rumo a uma postura lockeana de consentimento dos conectados e regente das relações interpessoais do mundo digital.

Com enfoque distinto, mas ainda incidente sobre o grande tema da disciplina jurídica do ciberespaço, Mariana Caetano S. S. Schwindt resenhou o livro de Clara-Luz Álvarez intitulado "Internet y Derechos Fundamentales", publicado em 2011, em que a internet assume a tríade função (i) de princípio constitucional autônomo, (ii) de garantia de direitos fundamentais à liberdade de expressão, educação, informação e saúde, ou mesmo, (iii) de parte integrante do serviço universal de telecomunicações.

A seção de informes setoriais deste quinto volume da Revista de Direito, Estado e Telecomunicações contempla a análise comparada de Rogério Assis Carmo sobre os institutos da autoridade ancilar (ancillary authority) do direito norte-americano e da teoria dos poderes implícitos conforme aplicada pelo Supremo Tribunal Federal, no Brasil, fazendo uso dos seguintes casos: American Library Association v. FCC 403 F. 3d 689 (2005); Comcast Corporation v. Federal Communications Commission 600 F. 3d 642 (2010); Federal Communications Commission v. Midwest Video Corp. 440 U.S. 589 (1979); Supremo Tribunal Federal do Brasil. Mandado de Segurança $n^{\circ}$ 26.547, j. 6/6/2007, Dje de 25/09/2009; Supremo Tribunal Federal do Brasil. Recurso Extraordinário n ${ }^{\circ}$ 603.583, j. 26/10/2011, Dje de 25/05/2012; United States v. Southwestern Cable Co. 392 U.S. 157 (1968); United States v. Midwest Video Corp. 406 U.S. 649 (1972). O informe 
conclui pela relevância do aprofundamento de estudo comparado entre tais institutos da autoridade ancilar e da teoria dos poderes implícitos como essencial para o devido equacionamento dos poderes das agências reguladoras brasileiras e consequente acréscimo de suas ponderações jurídicas à teoria da regulação.

Em sequência, consta um pormenorizado informe setorial de Jussara Costa Melo voltado ao registro histórico da proposta de criação do Serviço de Comunicações Digitais (SCD), que demonstra o processo de formação da vontade objetiva da Agência Reguladora brasileira e o papel decisivo dos atores setoriais, inclusive do Ministério das Comunicações, do Tribunal de Contas da União e, ao final, das empresas concessionárias de serviços de telecomunicações, no surgimento, elaboração e, finalmente, abandono - ou mudança de estratégia - de um processo de discussão da universalização da banda larga no Brasil que se estendeu por mais de seis anos.

Finalmente, a última seção da revista é dedicada à reunião das normas do setor de telecomunicações do ano de 2012 organizadas por temas e referenciadas a tabelas informativas. No início dessa seção, consta a lista de abreviaturas e siglas do setor de telecomunicações mantida pelo Grupo de Estudos em Direito das Telecomunicações da UnB, integrante do Núcleo de Direito Setorial e Regulatório (GETEL/UnB), bem como, ao final, foi inserido um exaustivo índice alfabético e remissivo das normas do setor no ano de 2012. Cada tema presente em dita seção contém referências a normas de todos os níveis e a atos administrativos correlatos identificados por símbolos criados pelo Núcleo de Multimídia e Internet da UnB.

\section{Filosofia da publicação}

A perspectiva orientadora da publicação consta de seu título como revista científica que reconhece a intercomunicação entre os papéis do Direito e do Estado no setor de telecomunicações. Mais ainda, a proposta de estudos jurídicos dirigida à interseção das rubricas estatal e telecomunicacional esboça uma concepção de direito regulatório em que o desenvolvimento setorial é visto como um empreendimento resultado da confluência de atores públicos e privados em meio a parâmetros jurídicos superiores responsáveis por sua classificação como um projeto público. Tem-se presente o princípio constitucional norteador da regulação setorial 
como um espaço de estudo do direito de liberdade política, que, dentre outras dimensões, incorpora ao verbo 'regular' a ação a ele correspondente de reconhecimento do dever do cidadão a aprender a se governar. O estudo do direito das telecomunicações tem por componente diretivo o significado do direito à autodeterminação e da virtude política.

Em outras palavras, a publicação não adota vieses predefinidos e, portanto, não se rende ao enfoque totalitário de esgotamento do sentido regulatório em mitos, sejam eles mitos assentados no fundamentalismo ou magia de mercado, sejam mitos assentados na suficiência quase exclusiva do Estado. A presente publicação, como espaço de discussão e encontro de pontos de vista, encontra-se aberta a todas as correntes. Se não se pode defender a suficiência de um mercado destacado de fatores institucionais jurídicos, também não se pode defender o pressuposto da suficiência do planejamento macro e microeconômico, que restringe as decisões privadas do setor a partir de uma administração burocrática gerencial centralizada incapaz de se adaptar às demandas de uma sociedade da informação. Em nenhuma destas hipóteses, o princípio constitucionalista participativo encontra-se respeitado. Ele somente se apresenta em sua plenitude quando se reconhece a regulação como um espaço institucional regulador de exercício da liberdade de participação política por todos os atores setoriais habilitados a se responsabilizarem pelo presente $\mathrm{e}$ futuro das telecomunicações.

A presente publicação apresenta-se, portanto, como espaço público de discussão e confluência de todos os pontos de vista seriamente fundamentados e capazes de elevar o estado da arte da discussão jurídicoregulatória de telecomunicações.

\section{O setor de telecomunicações no ano de 2012}

O ano de 2012 introduziu algo novo na dinâmica do setor de telecomunicações brasileiro: a multiplicação das fronteiras jurídicas de regulação.

Em 1995, as telecomunicações foram cindidas, por força da Emenda Constitucional $\mathrm{n}^{\circ}$ 8, de 1995 e especificadas via Lei Geral de Telecomunicações (Lei 9.472/97), em três grandes espaços regulatórios, quais sejam, o das telecomunicações em sentido estrito, o de controle do 
espectro de radiofrequências indiferente à divisão de serviços, cuja regulação competia à ANATEL segundo a política pública setorial definida nas instâncias ministerial, presidencial e congressual, e a radiodifusão, cuja regulação coube ao Ministério das Comunicações.

Porque tensa, essa fronteira regulatória dominava as tensões institucionais do setor de telecomunicações tanto em virtude da proeminência regulatória da ANATEL em termos estruturais, quanto de sua vocação para o avanço sobre aspectos técnicos de gerência do espectro de radiofrequências influentes em questões-chave da radiodifusão, em especial as referentes à transição da TV analógica terrestre para a digital, que fora resolvida por padronização de tecnologia digital associada à migração entre faixas de radiofrequências.

Tal era a proeminência dessa tensão institucional, que restavam amesquinhadas outras tensões, como a presente na relação entre os órgãos de segurança pública, de proteção do consumidor e a ANATEL no bloqueio de celulares em presídios, bem como a do tratamento do Sistema de Proteção ao Vôo, envolto na regulação partilhada entre a ANATEL e o Comando da Aeronáutica sobre as variações do serviço de telecomunicações aeronáutica.

O cenário de 2012 transformou decisivamente a polarização institucional quando se evidenciou a inserção progressiva da ANCINE sobre a regulação de fases anteriores à distribuição dos Serviços de Acesso Condicionado, bem como o realinhamento do Ministério das Comunicações no necessário entendimento com o Ministério da Cultura no que tange às políticas públicas referentes ao antigo gênero de serviços de TV por assinatura.

Mesmo a relação normalmente imperceptível de regulação conjunta do Sistema de Proteção ao Vôo e do serviço de telecomunicações aeronáuticas tomou novo formato com o movimento de privatização de parcela da infraestrutura de aeroportos nacionais. Por força do rearranjo do setor aeronáutico para ingresso de concessionárias privadas em aeroportos, foi alterada a Lei 6.009, de 26 de dezembro de 1973 pela Lei 12.648, de 17 de maio de 2012, produto da conversão da Medida Provisória $n^{\circ} 551$, de 22 de novembro de 2011, para fazer constar três tipos tarifários expressos pertinentes às telecomunicações na navegação aérea e de competência do Comando da Aeronáutica: a Tarifa de Uso das Comunicações e dos Auxílios à Navegação Aérea em Rota; a Tarifa de Uso das Comunicações e dos Revista de Direito, Estado e Telecomunicações, v. 5, n. 1, p. 1-28 (2013) DOI: https://doi.org/10.26512/lstr.v5i1.21561 
Auxílios-Rádio à Navegação Aérea em Área de Controle de Aproximação; e a Tarifa de Uso das Comunicações e dos Auxílios-Rádio à Navegação Aérea em Área de Controle de Aeródromo. A antes exótica regulação das telecomunicações aeronáuticas ingressou, em 2012, no espaço de precisão regulamentar demandado pela abertura do setor de infraestrutura aeroportuária.

A fronteira regulatória de maior projeção, entretanto, como não poderia deixar de ser, afirmou-se na regulação dos meios de comunicação de massa em meios confinados via o Serviço de Acesso Condicionado e o seu primo mais abrangente e extravagante aos olhares de regulação de infraestrutura telecomunicacional da ANATEL: a Comunicação Audiovisual de Acesso Condicionado trazida pela Lei 12.485, de 12 de setembro de 2011 e regulamentada por atuação da ANCINE ao final de 2011 e durante o ano de 2012.

As dificuldades de precisão das fronteiras regulatórias puderem ser evidenciadas na reação de operadoras à proposta de instrução normativa de regulamentação do SeAC pela ANCINE, em que a obrigação de fornecimento, por parte de empacotadoras, da lista de assinantes à ANCINE foi questionada pela operadora Telefônica por tratar a empacotadora como distribuidora, esta sim, detentora de relação direta com os assinantes, à medida que a relação jurídica existente na cadeia do audiovisual seria entre empacotadora e distribuidora, de um lado, e distribuidora e assinantes, de outro.

Esse exemplo foi um dentre muitos questionamentos sobre os limites regulatórios da ANCINE e da ANATEL no que se refere à condição peculiar do SeAC como serviço submetido, em diferentes camadas, a duas agências reguladoras.

$\mathrm{Na}$ mira da divisão de competências regulatórias em camadas de programação e distribuição, bem como da proibição, pela, Lei 12.485/2011, de sobreposição de atividade de programação e distribuição, encontram-se dois atores relevantes do setor: o Grupo Band, que então controlava a operação de TV por assinatura Sim TV, antiga TV Cidade, e possui canais próprios como o BandSports, BandNews e o Arte1; e a Sky, com canal eventual de esportes, o Sky Sports + , que se utilizava de conteúdo gerado por aquisição de direitos de eventos internacionais. 
Outro questionamento que surgiu quando da proposta de regulamentação do SeAC pela ANCINE adveio da redefinição do conceito de controladora na cadeia de TV paga, no que se refere à separação entre os mercados de conteúdo e distribuição prevista no art. $5^{\circ}$ da Lei 12.485/2011, mediante alteração da Instrução Normativa ${ }^{\circ}$ 91, de $1^{\circ}$ de dezembro de 2010 (IN 91) da ANCINE, pela Instrução Normativa no 101, de 29 de maio de 2012, para caracterizar como controladora tão somente a "titular de direitos de sócio que lhe assegurem, de modo permanente, preponderância nas deliberações sociais e poder de eleger a maioria dos administradores", retirando-se outros elementos de caracterização de controle, tais como o direito de veto, o voto em separado e o impedimento à verificação de quórum qualificado, abrindo, assim, espaço para que uma programadora como a Globosat pudesse se enquadrar na categoria de programadora independente.

De sua parte, a ANATEL regulamentou o SeAC, que, dentre outras medidas, previu que a adaptação dos contratos de serviços de TV por assinatura em sentido amplo (MMDS, TV a Cabo, DTH) obedeceria aos efeitos jurídicos incidentes sobre a renúncia, ou seja, por maioria de votos em decisão do Conselho Diretor da ANATEL, de 22 de março de 2012, vencida a Conselheira Emília Ribeiro, persiste a exigibilidade somente dos compromissos vencidos à data de adaptação das outorgas de TV por assinatura ao novo modelo do SeAC, dispensando-se o cumprimento de compromissos firmados quando da obtenção das licenças de TV por assinatura, cujo cumprimento não fosse exigível na data da migração.

No detalhe, o Regulamento do SeAC aprovado pelo Conselho Diretor da Anatel voltou atrás em diversas exigências esboçadas na consulta pública que o precedeu, decidindo pela: a) inexistência de obrigações de cobertura no novo serviço, eliminando-se metas de cobertura da TV a Cabo antes vigentes até a migração efetiva das prestadoras para o SeAC; b) a abertura de possibilidade de venda de decodificadores no varejo; c) a eliminação da obrigatoriedade de disponibilização de equipamento de recepção específico para os sinais de TV aberta quando eles não estivessem sendo carregados pela própria rede da operadora de $\mathrm{SeAC}$, persistindo somente a obrigação de que o sistema de recepção do SeAC não obstruísse a livre recepção da TV aberta; d) liberação da possibilidade de acúmulo de outorgas pelo mesmo grupo econômico, nos moldes de funcionamento do SCM, em que o projeto 
técnico apresentado pela proponente quando do pedido de outorga define a área de cobertura do serviço.

A regulamentação do SeAC, como era de se esperar, foi inserida em uma rede de normas correlatas de que depende para plena disciplina das peculiaridades do serviço, quais sejam: a disciplina do compartilhamento de redes de TV por assinatura, assim como o uso das redes das operadoras de telecomunicações pelo serviço, remetido ao futuro Plano Geral de Metas de Competição aprovado pela Resolução da ANATEL $\mathrm{n}^{\circ}$ 600, de 8 de novembro de 2012; a disciplina futura do valor da outorga e as condições de pagamento pela licença de SeAC; a disciplina do must-carry de canais abertos; a disciplina sobre o fornecimento de informações para a ANATEL para fins de acompanhamento e controle; a disciplina das sanções, remetida ao regulamento geral de sanções; a disciplina técnica do SeAC, inclusive qualidade das redes; e finalmente a disciplina da interatividade e multiprogramação. Notável, nesse ínterim, a posição da ANATEL de exigir o cumprimento das metas de cobertura das prestadoras de TV a Cabo que fossem exigíveis até a migração das licenças para o SeAC.

A crise nacionalmente divulgada de segurança pública do estado mais rico da federação - o Estado de São Paulo - não foi suficiente para desviar os holofotes do setor de telecomunicações para a disciplina técnica do bloqueio de celulares em presídios. No entanto, a iminência da Copa das Confederações, de 2013, e a proximidade da Copa do Mundo de 2014 e das Olimpíadas de 2016 a serem sediadas no Brasil desviaram a atenção da tensão regulatória do novo serviço abrangente da TV por assinatura para o resgate da eterna polêmica de expansão de espectro para o Serviço Móvel Pessoal na modalidade 4G, algo que projetou, já em janeiro de 2013, o primeiro problema regulatório de incompatibilidade entre a previsão de implementação da infraestrutura LTE das operadoras de telefonia móvel nas capitais da Copa das Confederações de 2013, em contradição à expectativa de liberação onerosa de frequências ocupadas por operadoras de Serviço de Distribuição de Sinais Multiponto Multicanal (MMDS), que perderam espaço com a redistribuição de faixas de frequência ocupadas por eles para a expansão da telefonia celular. Retomar-se-á este ponto mais à frente no tratamento da faixa de $2,5 \mathrm{GHz}$.

Portanto, para além da redefinição de fronteiras regulatórias entre a ANATEL e a ANCINE, entre o Ministério das Comunicações e o da 
Cultura, e entre as operadoras de telecomunicações e produtoras, programadoras e empacotadoras de conteúdo, as fronteiras entre os próprios serviços de telecomunicações foram realinhadas, avançando o Serviço Móvel Pessoal (SMP) por sobre o Serviço de Distribuição de Sinais Multiponto Multicanal (MMDS) e sobre a faixa de $450 \mathrm{MHz}$ para a expansão rural do SMP para a área definida como aquela compreendida dentro do raio de $30 \mathrm{~km}$ desde a borda de cobertura do STFC de cada município.

O avanço citado também foi conceitual, quando, durante o ano de 2012, a abrangência do Serviço de Acesso Condicionado (SeAC) fora discutida frente ao conceito de Serviço de Valor Adicionado (SVA), excluído da competência regulatória da ANATEL a partir da segmentação legal entre serviço de telecomunicações e SVA. A nova Lei do SeAC (Lei 12.485/2011) serviu de mote para a redefinição das atividades abarcáveis pela competência regulatória da ANATEL, em especial sobre aquelas compreendidas como vídeo oneroso por demanda e mídia móvel via internet.

Em outra seara, o redimensionamento das fronteiras institucionais regulatórias afigurou-se sob sua dimensão federativa, quando, em mensagem de abertura dos trabalhos legislativos de 2012 a Presidente da República fez menção à dedicação do Poder Executivo na resolução de conflitos dos prestadores de serviço com os detentores de infraestrutura e na perniciosa heterogeneidade de normas municipais de instalação de infraestrutura.

A mesma mensagem iluminou outra tensão de fronteira regulatória: a dos serviços, ao ressaltar a intenção do Poder Executivo de atualização da regulamentação infralegal da radiodifusão de 1963 para "integrar em um único regulamento os procedimentos relativos a todos os serviços de radiodifusão, seus ancilares e auxiliares, bem como outras evoluções visando à simplificação dos processos de outorga e pós-outorga". O tema foi retomado por várias vezes durante o ano de 2012 por parte do Ministro das Comunicações. No $26^{\circ}$ Congresso Brasileiro de Radiodifusão, Paulo Bernardo afirmou ser imprescindível a modernização da legislação de radiodifusão para que a dimensão jornalística e a dimensão de transmissão paga multimídia das comunicações eletrônicas, que não se enquadrariam 
nem na radiodifusão, nem nas telecomunicações, pudessem gozar de um marco regulatório apropriado.

Finalmente, o tema de idas e vindas sobre a extensão da competência regulatória da ANATEL e do Ministério das Comunicações sobre a radiodifusão foi sedimentado em um acordo de cooperação técnica, em junho de 2012, entre a agência reguladora e o órgão ministerial para que a ANATEL atuasse, por delegação, na análise de processos técnicos de engenharia referentes à fase de pós-outorga dos serviços de radiodifusão com o objetivo de acelerar o processo de renovação de outorgas. Essa medida foi antecipada por uma longa discussão entre as consultorias jurídicas do Ministério das Comunicações e da ANATEL, ora ampliando-se os poderes da agência para fiscalização das redes de radiodifusão, ora entregando-se todo o poder de acompanhamento para o Ministério das Comunicações. O acordo de cooperação técnica citado foi mais uma etapa que promete estabilizar a prática de averiguação técnica no acompanhamento das concessões de radiodifusão, persistindo o entendimento de que o Ministério das Comunicações seria o competente para tanto, embora incapaz de realizá-lo por si só.

As prioridades elencadas pela ANATEL em fevereiro de $2012^{1}$ inauguraram o ano com a primeira questão delicada de aplicação do art. $5^{\circ}$, da Lei 12.485/2011, que vedara às empresas de radiodifusão, programadoras ou produtoras de conteúdo, o exercício de controle sobre empresas prestadoras de serviços de telecomunicações em sentido estrito. Em pedido de anuência prévia à assunção, pela Embratel, do controle da Net Serviços, o Conselho Diretor da ANATEL antecipou o entendimento, em 26 de janeiro de 2012, de que caberia à agência unicamente a análise dos limites de

${ }^{1}$ As prioridades acenadas pela agência em fevereiro de 2012 foram: o lançamento do edital das faixas de $2,5 \mathrm{GHz}$ e $450 \mathrm{MHz}$; a elaboração do Regulamento do SeAC até 9 de março de 2012, conforme previsto na Lei 12.485/2011; a aprovação do Regulamento do Plano Geral de Metas de Universalização; a aprovação do Regulamento de Prestação do STFC fora da área de tarifação básica; a revisão do Regulamento do AICE; a revisão do Regulamento do Fator X; a aprovação do Regulamento de Fiscalização e Sanções; a reestruturação interna da ANATEL; a aprovação do Regulamento do Plano Geral de Metas de Competição; a revisão do Regulamento de Exploração Industrial de Linha Dedicada e do Regulamento do Serviço de Comunicação Multimídia; a aprovação do Regulamento de Bens Reversíveis. 
controle de radiodifusoras no que se refere à distribuição, não atingindo, desse modo, as atividades de empacotamento, relegadas à regulação da ANCINE. Com isso, os critérios de caracterização do controle no setor de comunicação audiovisual, no Brasil, passaram a depender do entendimento setorializado tanto da ANATEL quanto da ANCINE.

Em outra frente de fixação de fronteiras entre detentoras ou não de poder de mercado significativo, o Conselho Diretor da ANATEL, em janeiro de 2012, fixou o direito de prestadoras de SMP sem Poder de Mercado Significativo (PMS), segundo a interpretação do art. 18 do Regulamento de Remuneração pelo Uso de Redes de Prestadoras do SMP, aprovado pela Resolução $\mathrm{n}^{\circ} 438$, de 10 de junho de 2006, de fixar o valor da VU-M até $20 \%$ maior imediatamente, não sendo atingidas pela exigência de fixação prévia de modelo de custo. A decisão dizia respeito à disputa entre a Unicel e a Telefônica, com a pretensão de se aplicar a outras operadoras de menor escala, como Sercomtel, Algar Telecom e Nextel.

Não passou em branco o tema da neutralidade de rede, mas, no ano de 2012, ele foi revestido da discussão de preservação das competências regulatórias da ANATEL, que foram questionadas durante a tramitação do Marco Civil da Internet na Câmara dos Deputados, em especial no que se refere à previsão contida no relatório do deputado Alessandro Molon (PT/RJ), em que o CGI.br teria a competência de emitir recomendações sobre os casos em que poderia haver flexibilização da neutralidade de rede. Vozes em defesa da preservação do art. $9^{\circ}$ do projeto de então alertaram para o fato de que caberia ao CGI.br, no uso de seu conhecimento sobre a internet, definir questões que dissessem respeito à região que se encontra acima da rede, conforme expressão do diretor presidente do NIC.br, Demi Getschko. A preservação da competência do CGI.br permitiria, na visão de seus defensores, o tratamento prioritário de aplicações em tempo real, como o VoIP. O relatório para apreciação da Comissão Especial de análise do Marco Civil da Internet elaborado pelo deputado Alessandro Molon, em meio às polêmicas, deixou a questão das exceções à neutralidade de redes para serem disciplinadas por decreto, substituindo-se a referência à "respeitar as recomendações do CGI.br" pela expressão "ouvir as recomendações do CGI.br", explicitando que a matéria seria regulamentada por decreto. Também foram retirados do relatório final dispositivos que previam a possibilidade de um provedor bloquear conteúdos sem ordem 
judicial por iniciativa própria ou mediante acordos. O Marco Civil, entretanto, não prosperou em 2012 e os augúrios de 2013 não parecem acenar com um solução definitiva para a questão.

A proteção da indústria nacional também foi afetada por medidas de fixação de fronteiras - literalmente - para terminais celulares não homologados pela ANATEL. Foi divulgado, em dezembro de 2012, com o apoio do SindiTelebrasil, e sob o discurso ministerial de proteção do consumidor contra aparelhos piratas de má qualidade, o desenvolvimento de sistema mediante o que, através do número de identificação IMEI de cada aparelho celular, a operadora nacional detectaria quais deles foram efetivamente homologados pela ANATEL e bloquearia, para os novos aparelhos, a sua habilitação. No embate entre a globalização econômica e a regulação nacional, esta tem levado vantagem a passos largos.

Aliás, o ano de 2012 foi palco para um evento internacional inédito, em que países de peso negaram-se a assinar o texto final do novo tratado mundial contendo os Regulamentos de Telecomunicações Internacionais (ITRs), decorrente de Conferência Mundial de Telecomunicações Internacionais (WCIT-12), da União Internacional de Telecomunicações, realizada em Dubai em dezembro de 2012. Com o placar de 89 assinaturas contra 55 não signatários, os maiores mercados de telecomunicações do mundo discordaram do texto, dentre eles, Estados Unidos, Canadá, União Europeia, os países escandinavos, Reino Unido, Japão, Índia e Austrália. Embora de acordo em temas como os de transparência para o roaming internacional, fixação de números globais de emergência e atualização dos acordos de cobrança para tráfego internacional de telecomunicações, os países citados saíram da mesa de negociação quando da aprovação de uma resolução anexa aos ITRs, que firmava a UIT como instituição central e ativa na definição do futuro da internet. A acusação de que a resolução seria prejudicial à preservação das liberdades da internet e que ela teria pego de surpresa as delegações dos maiores mercados de telecomunicações do mundo promete criar uma nova dinâmica que tende ao enfraquecimento da UIT como órgão de convergência da negociação das políticas de telecomunicações. 


\section{As faixas de 2,5 GHz e 3,5 GHz}

Outros assuntos tradicionais do setor ocuparam o interesse regulatório, em especial, a expansão do espectro para o Serviço Móvel Pessoal. As dificuldades da ANATEL na definição de metodologia de cálculo para uso da faixa de 2,5 GHz foram enfrentadas, ao menos em parte, em 2012. Em 2009, a ANATEL havia renovado as licenças de MMDS na faixa, remetendo para ato posterior a fixação do valor pela renovação, gerando, no caso da Sky, a judicialização da questão e depósito em juízo tão somente do preço público pelo direito de uso da radiodiofrequência (PPDUR).

Em 2011, em maio, a ANATEL aprovara o pedido da Sky de licença para SCM na faixa de $2,5 \mathrm{GHz}$, mas sem especificar ainda a forma de liberação e de cobrança. 2012 foi o ano em que pedidos de licença de SCM por parte de antigas prestadoras de MMDS foram colocados à prova em meio a um conselho diretor da Anatel dividido frente a dúvidas sobre: a) a necessidade de pagamento pelo uso da radiofrequência associada ao SCM na faixa de 2,5GHz (Bechara e Emília Ribeiro entendendo que o pagamento pelo uso da faixa seria necessário e o presidente da ANATEL questionando o porquê disso, já que a prestadora já era autorizada de MMDS); b) o prazo da licença de SCM - se seria ou não vinculado ao da licença de MMDS correspondente; c) o valor da autorização de uso de radiofrequência de $2,5 \mathrm{GHz}$ pelo método do valor presente líquido (VPL); dentre outras questões jurídicas levantadas nas sessões do conselho diretor em que tais licenças foram colocadas em votação ainda no primeiro semestre de 2012.

Definidas as diversas questões, inclusive o direito de preferência de compra das operações de MMDS das empresas que obtivessem faixas nacionais ou regionais de 2,5 GHz nas mesmas localidades das licenças de MMDS, o leilão da faixa de $2,5 \mathrm{GHz}$ ocorreu em junho de 2012, quando a faixa de $450 \mathrm{MHz}$ não obteve interessados e passou a ser tratada como um dever de abrangência das adquirentes da faixa de 2,5 GHz.

Em 20 de agosto de 2012, a Claro - operadora de SMP - lançou comercialmente suas primeiras redes LTE 4G em cidades-teste - Campos do Jordão, Búzios e Paraty -, nos Estados de São Paulo e Rio de Janeiro, tendose declarado, à época a intenção de avaliação das redes em tais cidades para posterior lançamento comercial das redes $4 \mathrm{G}$ nas seis cidades-sede da Copa das Confederações. 
A faixa de 3,5 GHz todavia permaneceu no limbo. Tendo sido licitada para algumas empresas em 2003 (Embratel, Neovia e Vant, adquirida pela Oi), a licitação que se seguiu em 2006 foi suspendida por determinação do Tribunal de Contas da União (TCU) sob fundamento de deficiência metodológica na fixação do preço mínimo para a faixa. Em 2012, a solução para a licitação da faixa, prometida pelo presidente da ANATEL e pelo Ministro das Comunicações, tornou-se ainda mais complicada, à medida em que grupos técnicos formados para análise de interferências em antenas parabólicas confirmaram que a proteção contra interferências prejudiciais em tais antenas demandaria melhorias na planta instalada de antenas parabólicas, mediante instalação de filtros e ajustes técnicos com as operadoras de celulares em todo o país. O caso dos $3,5 \mathrm{GHz}$ abriu o veio de questionamentos sobre a formação e capacidade operacional técnica da ANATEL para detecção, a priori, de interferências prejudiciais, já que a faixa de $3,5 \mathrm{GHz}$ não fora antes plenamente ocupada por questões outras de fixação de preço mínimo, sem que tivesse havido posicionamento da ANATEL sobre interferências prejudiciais.

\section{Déjà vu}

A Constituição Federal foi novamente lida em 2012 por incentivo das tensões institucionais de fronteira regulatória entre a radiodifusão e o novo SeAC após seis anos de espera para reativação do Conselho de Comunicação Social. Sua função opinativa compulsória para regulamentação da TV por assinatura explica o movimento espasmódico de renascimento do Conselho. Em 17 de julho de 2012, o presidente do Congresso Nacional, senador José Sarney, nomeou os 13 novos integrantes do Conselho de Comunicação Social, que se encontrava inativo por vacância de seus membros desde 2006. Sua primeira reunião ocorreu em 3 de setembro de 2012.

\section{Convergência}

O tema da unificação de licenças voltou a ocupar uma posição de relevo ao ser defendido por um conselheiro da ANATEL que as licenças de STFC, SCM, SMP e SME fossem unificadas em um serviço único prestado em regime privado, sob o fundamento de que a prestação em regime público do STFC estaria em declínio, dificultando a regulação do setor por separar a 
telefonia da banda larga fixa, bem como em virtude do melhor jogo de negociação de que disporia a ANATEL quando se trata de serviços privados via metas de abrangência versus o ônus de preservação do equilíbrio econômico-financeiro próprio à prestação de serviços de telecomunicações em regime público.

No campo jurisprudencial, em junho de 2012, o Tribunal de Justiça de São Paulo, provocado por ação da TIM Participações contra a Nextel, confirmou decisão do juízo singular, embora sem pronunciamento sobre o seu mérito, vedando a comercialização de serviços de SME da Nextel a pessoas físicas individualmente, preservando, entretanto, a comercialização a pessoas jurídicas ou a grupos de pessoas físicas ligadas a uma atividade específica. Neste particular, a regulamentação por serviços, dividindo-se a utilidade fruível por parte do SMP como destinada ao público em geral, em oposição ao SME, como um serviço de despacho definido para um público específico, tem servido como um escudo das empresas celulares contra o ingresso da Nextel no mercado de telefonia móvel. No ano de 2012, em várias ocasiões, a Nextel foi cobrada, no âmbito regulatória da ANATEL, quanto à comprovação de que seus clientes seriam pessoas jurídicas ou grupos de pessoas físicas ligadas a uma atividade específica.

A aplicação dos arts. $5^{\circ}$ e $6^{\circ}$ da Lei do SeAC foi questionada em ações diretas de inconstitucionalidade interpostas pela Associação Brasileira de Radiodifusores (Abra) e pela NeoTV perante o Supremo Tribunal Federal. Nela, os postulantes atacaram os preceitos de vedação de que empresas de radiodifusão e conteúdo controlassem empresas de telecomunicações e de que empresas de telecomunicações controlassem e tivessem mais de $30 \%$ de empresas de conteúdo e radiodifusão. Especialmente interessadas no posicionamento do STF encontravam-se o Grupo Bandeirantes, controlador de empresa de radiodifusão e de operadoras de cabo SimTV, como também pequenos operadores de cabo controlados por grupos locais de radiodifusão, e mesmo operadoras nacionais como a Sky e OiTV, que produzem seus próprios canais locais e canais de relacionamento com o cliente. A regra de vedação de propriedade cruzada passou a ter eficácia a partir do dia 12 de setembro de 2012 e os atores setoriais interessados, entre eles, o Grupo Bandeirantes, anunciaram, na primeira semana de setembro, que aguardariam a decisão do STF antes de tomar providências no que se refere ao cumprimento da Lei 12.485/2011.

Revista de Direito, Estado e Telecomunicações, v. 5, n. 1, p. 1-28 (2013)

DOI: https://doi.org/10.26512/lstr.v5i1.21561 


\section{Neutralidade de redes}

A velha questão regulatória da priorização de preços/competição versus a priorização de expansão do acesso ressurgiu em caso específico de regulamentação da Exploração Industrial de Linha Dedicada (EILD).

O tema da neutralidade de redes permaneceu pautando o setor pela voz de representantes da Oi, que viu o novo regulamento de EILD, em especial a imposição dos valores de referência para oferta de rede no atacado via EILD, como um desincentivo à instalação de redes por parte de grandes operadoras já instaladas, como a Claro/Embratel, a Vivo/Telefônica e a TIM, que ao invés de ampliarem suas redes, estariam se utilizando das regras do regulamento para avançarem sobre novos mercados via redes da Oi. A aplicação da neutralidade de redes para operadoras já estabelecidas seria prejudicial, sob o ponto de vista da Oi, à implantação de nova infraestrutura de rede.

Por outro lado, o incentivo regulatório à implantação de novas redes de fibra óptica mediante o chamado feriado regulatório introduzido pelo Plano Geral de Metas de Competição (PGMC), que liberou as redes de fibra óptica do dever de compartilhamento, foi questionado pelas operadoras quanto à sua proposta de efetivamente promover os investimentos no setor, haja vista inexistir, no corpo dispositivo do regulamento do PGMC, referência ao prazo de 9 anos de feriado regulatório constante dos estudos realizados pela área técnica da Agência e conhecido via anexos ao regulamento do PGMC. O entendimento exarado por vozes da Agência, entretanto, externava a posição de que presente ou não no corpo dispositivo do regulamento do PGMC, à Agência caberia revisar este prazo quando das revisões periódicas do plano.

\section{Qualidade dos serviços}

Em 28 de fevereiro de 2012, foi divulgada a Entidade Aferidora da Qualidade (EAQ) selecionada pela comissão de seleção composta por representantes das operadoras para medição da qualidade da banda larga no SMP e SCM: a PriceWaterhouse Coopers, com apoio tecnológico da SamKnows, vencendo uma disputa com o Nic.Br, a ABR Telecom e a ISPM-Serviço de Informática. 
A escolha da EAQ foi um acontecimento relevante, mas pálido quando comparado ao acontecimento que galvanizou o setor e teve lugar em julho de 2012, quando a Superintendência de Serviços Privados da ANATEL determinou cautelarmente a suspensão da comercialização e ativação de acessos do Serviço Móvel Pessoal de três das operadoras - TIM, Oi e Claro -, com vigência a partir de 23 de julho de 2012. A medida determinou a suspensão das vendas da TIM em 19 estados da federação, da Oi em 5 estados da federação e da Claro em 3 estados da federação, pautando-se no critério do pior desempenho por unidade da federação. Todas as operadoras, entretanto, foram instadas a apresentarem, no prazo máximo de 30 dias, um Plano Nacional de Ação de Melhoria. A notícia surgiu em meio a críticas quanto à eficácia da medida, bem como quanto à falta de um procedimento regular de fiscalização por amostragem da qualidade dos serviços móveis do país, haja vista o desvio de parcela considerável da arrecação derivada das taxas de fiscalização e de outras fontes componentes do FISTEL para composição de superávit primário do Governo Federal em detrimento de investimento na estrutura fiscalizatória da agência reguladora. Houve também crítica quanto à lentidão governamental em ultrapassar os obstáculos de expansão da instalação de antenas celulares por leis municipais espalhadas por todo o país. Medida cautelar pedida à Justiça Federal, em Brasília, pela TIM contra a decisão da ANATEL foi negada sob o argumento de que se tratava de medida necessária, embora devesse ser limitada no tempo. TIM, Oi e Claro foram autorizadas a retomarem a comercialização de novas linhas a partir do dia 3 de agosto, mediante publicidade dos planos de melhoria e investimento e promessa da ANATEL de contínua fiscalização dos compromissos firmados, bem como estimativa oficial da ANATEL de que a medida cautelar teria resultado no investimento de $\mathrm{R} \$ 4$ bilhões para melhoria das operadoras oriundos de antecipação e remanejamento de investimentos de outras áreas, inclusive marketing. Dentre as medidas divulgadas pelas operadoras em cumprimento aos planos de melhoria aprovados pela ANATEL, a TIM se comprometeu a realocar investimentos para aumento da capacidade e melhoria da qualidade da rede, a Claro divulgou a antecipação de investimentos previstos para o final de 2013 e a implementação de um cabo submarino entre Brasil e Estado Unidos para escoamento de tráfego de dados e ligações internacionais, e a Oi, um conjunto de medidas gerais de atualização 
tecnológica e aumento da cobertura. Todas elas foram uníssonas em comunicar que dariam prioridade na prestação de serviços de qualidade durante a Copa do Mundo e as Olimpíadas.

Enquanto, de um lado, a ANATEL cobrava das operadoras planos de investimento para solução da crise de percepção de qualidade dos serviços móveis, o TCU cobrava da ANATEL a mesma espécie de atitude administrativa, agora no momento gerencial. Em julho de 2012, em acórdão do TCU publicado em 24 do mesmo mês no Diário Oficial da União, afirma-se o descumprimento de parcela das recomendações exaradas em acórdãos do TCU de 2005 e 2006, em especial, medidas de aperfeiçoamento do processo de acompanhamento dos indicadores de qualidade informados pelas empresas na forma de auditorias ou sistemas de monitoramento, implementação de procedimento sistemático e periódico de acompanhamento do cumprimento das demandas dos usuários sobre qualidade do serviço e do atendimento pelas operadoras, a criação de mecanismos sistemáticos de acompanhamento rigoroso da resolução dos problemas apontados nos relatórios de fiscalização, bem como a recomendação mais significativa de um Estado planejador e gerencial na clássica dicção do Estado Administrativo: a tomada de providências para assegurar que as sanções tenham o condão de garantir a correção e a prevenção das irregularidades.

\section{Remuneração pelo uso de redes}

O novo regulamento de Remuneração pelo Uso de Redes de Prestadoras do STFC foi publicado no Diário Oficial da União, de 9 de maio de 2012, para entrada em vigor diferida em 90 dias de sua publicação, alterando a remuneração da Tarifa de Uso da Rede Fixa (TU-RL), ou seja, a remuneração pela terminação das chamadas nas redes prestadoras do STFC. Até então, adotava-se o chamado bill and keep parcial, em que a remuneração pelo uso de rede dependia da constatação de um desbalanceamento de $45 \%$ contra $55 \%$ no tráfego entre operadoras. A partir da entrada em vigor do novo regulamento, as prestadoras de origem de chamadas passam a pagar pelo uso da rede das prestadoras de destino somente quando o percentual de desbalanceamento ultrapassar 75\%, projetando-se a implantação do bill and keep pleno para janeiro de 2014, 
quando não haverá mais pagamento de tarifa de interconexão entre as operadoras.

\section{Reversibilidade nas concessões do STFC}

As inúmeras dúvidas, acusações e defesas sobre a deficiência governamental e falta de transparência empresarial no acompanhamento dos bens reversíveis das concessões de STFC finalmente transpareceu números palpáveis, quando, em 21 de setembro de 2012, a ANATEL divulgou os dados colhidos com as operadoras referentes aos bens reversíveis.

A identificação dos valores de aquisição e contábil atual dos bens reversíveis de cada operadora foram os seguintes, sinteticamente: Oi (R\$ 58,3 bilhões de bens reversíveis adquiridos e $\mathrm{R} \$ 7,3$ bilhões em bens reversíveis não amortizados ou depreciados); Telefônica ( $\mathrm{R}$ \$38,9 bilhões na aquisição e R \$ 6,7 bilhões após amortizações e depreciações); Embratel (R \$ 9,3 bilhões de bens na aquisição e $\mathrm{R} \$ 2,9$ bilhões em valores contábeis atualizados); CTBC (R \$ 1,2 bilhões em valores de aquisição e $\mathrm{R}$ \$ 259 milhões em valores contábeis após depreciação e amortização); e Sercomtel ( $\mathrm{R} \$ 309$ milhões em valores adquiridos e $\mathrm{R} \$ 76$ milhões em valores atualizados).

Em meio à divulgação da lista de bens reversíveis, surgiu como ponto de fricção entre ANATEL e operadoras de STFC a definição da infraestrutura de banda larga passível de inserção dentre os bens reversíveis. Enquanto para a ANATEL, todo o investimento em infraestrutura pela qual trafega o serviço de voz seria reversível, para as operadoras, as redes de fibra óptica não deveriam ser computadas na lista de bens reversíveis por estarem predominantemente dedicadas ao tráfego de dados via Serviço de Comunicação Multimídia. Não por acaso, a lista de bens reversíveis declarada pelas operadoras fora composta predominantemente por infraestrutura de cabos de par trançado de cobre.

Não surpreendeu, portanto, o movimento seguinte anunciado publicamente pela primeira vez em outubro de 2012 pelo presidente da ANATEL, João Rezende, sugerindo a alteração do marco legal das telecomunicações antes de 2025, ano de vencimento das concessões de STFC, para extinção da figura dos bens reversíveis, sob o fundamento de que o tráfego nas redes fixas estaria diminuindo de $8 \%$ a $10 \%$ ao ano e, com isso, o valor dos bens reversíveis. Esse movimento somou-se ao de incentivo Revista de Direito, Estado e Telecomunicações, v. 5, n. 1, p. 1-28 (2013)

DOI: https://doi.org/10.26512/lstr.v5i1.21561 
às concessionárias para consolidação de atividades sob um CNPJ único, após a alteração do art. 86 da LGT pela Lei 12.485/2011, do SeAC. A dificuldade regulatória por segmentos de serviços resultou, em 2012, na mensagem do regulador por preferir acompanhar o movimento convergente de serviços e suas prestadoras, desembocando na atitude mais significativa da proposta de extinção dos bens reversíveis para adoção de modelo regulatório único indiferente ao regime jurídico dos serviços.

A postura da Agência condiz com o instrumento criado pela LGT de assimilação ao regime privado de prestação da fórmula regulatória via classificação do interesse envolvido: serviços de interesse coletivo versus restrito a serem garantidos por mecanismos de separação contábil e funcional. No caso da autorização dada pela ANATEL de consolidação das operações da Sercomtel sob um mesmo CNPJ em 2012, um dos condicionamentos para implementação da operação fora o da separação contábil para o fim de se dar visibilidade à utilização de infraestrutura fixa pelos serviços móveis, indicando que, para grandes operadoras que seguissem o mesmo caminho da consolidação, seria exigível também a separação funcional. $\mathrm{O}$ incentivo às consolidações advêm de ganhos tributários de operação conjunta dos serviços e uso de infraestrutura e de sua integral assimilação no preço da assinatura básica.

Após ter propulsionado movimentos de esclarecimento da natureza jurídica do backhaul subsidiado por troca de metas de universalização do STFC na última renovação das concessões do setor, como também de ter colaborado para a definitiva tomada de contas da ANATEL sobre o rol de bens reversíveis das concessionárias de STFC, a ação civil pública $\mathrm{n}^{\circ}$ 2008.34.00.011445-3 - nova numeração 0011396-13.2008.4.01.3400 -, autuada em 11 de abril de 2008 e motivada pela troca de metas de universalização dos contratos de concessão de STFC, mediante, dentre outras medidas, a diminuição das obrigações de instalação de TUPs e TAPs pela implantação de infraestrutura de backhaul no país, foi extinta sem julgamento de mérito por perda superveniente do interesse de agir da requerente ProTeste, à medida que a ação civil pública atacava o art. 13 dos decretos de números 4.769/2003 e 6.424/2008, combinado com os aditamentos aos contratos de concessão firmados em 8 de abril de 2008, que foram ou revogados pelo Decreto $n^{\circ} 7.512 / 2011$, que aprovou o novo Plano Geral de Metas para a Universalização do Serviço Telefônico Fixo 
Comutado prestado no Regime Público (PGMU), ou alterados, como foi o caso dos aditamentos aos contratos de concessão adequados às novas metas de universalização do Decreto $\mathrm{n}^{\circ}$ 7.512/2011.

A demora da decisão judicial reflete a fraqueza dos instrumentos processuais disponíveis ao Judiciário - ou a fraqueza hermenêutica dos que fazem uso deles - para perícia sobre o backhaul contruído pela troca de metas de universalização, quando a sentença de extinção do processo atribuiu, em parte, a perda de objeto, à "dificuldade de se localizarem profissionais dispostos a assumir o encargo [de periciarem o backhaul], o que passou a consumir o processo desde o ano de 2010 até a resposta da UNICAMP, recebida depois da edição do Decreto $\mathrm{n}^{\mathrm{o}}$ 7.512/2011 (fls. 2487/2488), termin[ando] por fazer com que os atos impugnados deixassem de existir". Encontrado o bode expiatório para a ineficiência e formalismo do Poder Judiciário, este não decidiu sobre a natureza jurídica do backhaul, embora não tenha deixado de se pronunciar sobre o paradoxal posicionamento das operadoras de STFC, que concordaram com a Pro Teste, ao reconhecerem que o backhaul seria suporte para o Serviço de Comunicação Multimídia (SCM) ao invés de configurar suporte para o STFC, conforme defenderam, durante toda a tramitação do processo e via normatização do PGMU de 2011, a União e a ANATEL. A prova pericial exigida pelo juízo, portanto, somente se justificou pela resistência da União e da ANATEL em considerarem o backhaul como suporte do SCM, ao invés do STFC. Se a posição da Pro Teste e das operadoras fosse vitoriosa na ação, a ANATEL teria sido compelida a apropriar a diminuição do ônus das metas de universalização à tarifa de telefonia fixa em benefício dos consumidores de STFC, ao invés de se contentar com o investimento das operadoras no backhaul público. Ao que tudo indica, a questão do destino da liberação de ônus de metas de universalização - para o backhaul ou para as tarifas - se alongará no tempo rumo ao esquecimento. Até 2025 , quando está prevista a renovação dos contratos de concessão em vigor, ainda há espaço para rediscussão da questão do aproveitamento econômico da liberação de metas de universalização trazidas no Plano Nacional de Banda Larga do Governo Federal.

Não obstante o imbrólio sobre a natureza jurídica do backhaul, a urgência de construção da infraestrutura de suporte ao STFC, ou melhor, da banda larga fixa prestada via SCM, para suprimento da deficiente Revista de Direito, Estado e Telecomunicações, v. 5, n. 1, p. 1-28 (2013)

DOI: https://doi.org/10.26512/lstr.v5i1.21561 
infraestrutura das concessionárias e autorizatárias de STFC, persistiu na agenda governamental. Após a aprovação de que as contratações de capacidade satelital do satélite geoestacionário brasileiro Br1Sat fossem feitas com dispensa de licitação via decisão do Conselho de Defesa Nacional (CDN), foi esclarecido pelo secretário de telecomunicações do Ministério das Comunicações (Maximiliano Martinhão) que dos 55 Gbps de capacidade de banda Ka disponíveis no satélite, em torno de dois terços seriam destinados à prestação de serviços de backhaul a provedores de acesso no âmbito do PNBL, mantendo-se o restante para utilização por órgãos de governo e empresas públicas para o tráfego de dados estratégicos. Dentre os órgãos e entes consultados para uso do satélite para tráfego de dados estratégicos, estavam: Abin; Presidência da República; Ministério das Comunicações, inclusive o Gesac; Ministérios do Desenvolvimento, MeioAmbiente, Previdência, Minas e Energia, Educação, Ciência e Tecnologia, Saúde e Justiça; Petrobrás; Correios; Datasus; bancos estatais; polícia rodoviária federal, entre outros. $\mathrm{O}$ anúncio veio cercado de cuidados em evidenciar que o fornecimento de capacidade satelital para tráfego de comunicação dos órgãos de governo se restringiria a dados estratégicos, mantidos todos os contratos de provimento de capacidade de satélite em vigor com operadores privados, cabendo a cada órgão estatal, ao final de tais contratos, licitar novos serviços, já que o satélite administrado pela Telebras somente serviria ao provimento de capacidade satelital para dados estratégicos.

\section{Transparência ou sigilo dos PADOS?}

Em sequência ao movimento do ano anterior de publicização das reuniões do Conselho Diretor da ANATEL e da legislação e regulamentação sobre transparência de processos públicos, o art. 79 do Regimento Interno da ANATEL foi anulado às pressas pelo Conselho Diretor em $1^{\circ}$ de março de 2012 para tentar contornar os efeitos da derrubada de liminar, que determinara a abertura dos processos de descumprimento de obrigações em curso na Agência. O SindiTelebrasil argumentava estar-se descumprindo o art. 79, de sigilo dos procedimentos administrativos para apuração de descumprimento de obrigações (PADOs), quando da abertura das reuniões do Conselho Diretor. Defendeu-se, então, que a anulação do art. 79 tornaria sem objeto a ação do SindiTelebrasil, persistindo a publicidade das reuniões 
do Conselho Diretor que discutissem PADOs, bem como do próprio processamento dos PADOs no âmbito da agência reguladora. Essa manobra permitiu que a prática em vigor desde outubro de 2011 de transmissão das sessões do Conselho Diretor via internet e em telões dos escritórios regionais da ANATEL não fosse interrompida. Em junho de 2012, por um dia, os processos administrativos para apuração de descumprimento de obrigações (PADOs) não puderam constar da parte pública das reuniões do Conselho Diretor da ANATEL por força de liminar, logo em seguida cassada por decisão do Tribunal Regional Federal da $2^{\mathrm{a}}$ Região, que deu efeitos suspensivos à liminar que proibia a divulgação de dados dos PADOs em que constassem associadas da Associação Brasileira de Telecomunicações (Telebrasil). A decisão do TRF da $2^{\mathrm{a}}$ Região foi acompanhada de desistência da ação por parte do SindiTelebrasil, alegando pressões do governo federal pelo descontentamento devido à interferência na política de transparência das reuniões do Conselho Diretor da ANATEL. Ao final, como solução de compromisso, a ANATEL comprometeu-se a analisar criteriosamente se há dados sensíveis nos PADOs em tramitação, além de prometer analisar com maior celeridade os pedidos de sigilo, desde que fundamentados.

\section{Tributação e prognoses políticas}

No que se refere à política tributária, notou-se o movimento antecipado de desoneração tributária por antecipação de prognoses políticas. A proposta de desoneração da taxa de fiscalização de instalação em conexões M2M (machine-to-machine) seguiu a lógica regulatória de antecipação das dificuldades políticas em se desonerar o setor mais tarde, quando tais taxas chegassem a valores apetitosos para fins de finanças públicas. Neste particular, o processo de apreciação da medida provisória de desoneração tributária do PNBL serviu para pontuar um pressusposto regulatório de primeira grandeza: o planejamento tributário do setor correlato a prognoses do jogo político de desoneração tributária futura.

\section{TV digital}

Distantes três anos da previsão de finalização da transição para a TV digital terrestre, um novo posicionamento governamental sobre o cronograma de desligamento (switch off) dos canais da radiodifusão Revista de Direito, Estado e Telecomunicações, v. 5, n. 1, p. 1-28 (2013) DOI: https://doi.org/10.26512/lstr.v5i1.21561 
analógica deixou de ser especulação e passou a constituir o discurso oficial do Ministério das Comunicações a partir de agosto de 2012: o desligamento dos canais analógicos foi previsto de modo progressivo, antecipado para 2015 nas grandes capitais e protelado para além de 2016 em outras localidades. Até o final de 2016, todavia, previu-se o desligamento dos canais analógicos para 1.021 cidades brasileiras, alcançando grande parte da população nacional.

A liberação das frequências associadas à radiodifusão analógica não seguiu a mesma linha de raciocínio, haja vista a mobilização das radiodifusoras em torno ao tema das possíveis interferências da prestação de serviços móveis de quarta geração nas transmissões da TV aberta. Dos canais de UHF ocupados pelas radiodifusoras em 2012 (14 a 59, por TVs comerciais, e 60 a 69 , por TVs públicas), as operadoras de telecomunicações esperavam ficar, após o desligamento dos canais analógicos, com a faixa correspondente aos canais 14 a 52, que corresponderia ao dividendo digital, ou seja, às frequências liberadas pela digitalização da TV aberta. No congresso da Sociedade Brasileira de Engenharia de Televisão (SET), no dia 21 de agosto de 2012, foi apresentado estudo de interesse das radiodifusoras, propugnando a necessidade de aumento do espectro disponível para a migração dos canais analógicos para os digitais, em especial, em grandes conglomerados urbanos. A luta pelo uso do dividendo digital finalmente tomou a forma de estudos técnicos, demonstrando a demanda das radiodifusoras pela continuidade de uso da faixa de $700 \mathrm{MHz}$.

\section{Previsões do setor de telecomunicações}

A prognose do setor de telecomunicações brasileiro pode ser esboçada, embora de forma ainda vaga e como reflexo de cálculos governamentais de projeção de investimentos, nos programas temáticos do Plano Plurianual do Governo Federal para o período de 2012 a 2015. Quando do detalhamento dos Programas Temáticos do Anexo I da Lei 12.593/2012 (PPA 2012-2015), o Programa 2025, intitulado Comunicações para o Desenvolvimento, a Inclusão e a Democracia, contém os seguintes objetivos: a) Objetivo 0751 Expandir a infraestrutura e os serviços de comunicação social eletrônica, telecomunicações e serviços postais, promovendo o acesso pela população e buscando as melhores condições de preço, cobertura e qualidade, mediante alcance da meta de $90 \%$ de emissoras de televisão analógicas digitalizadas 
em todas as regiões do país, de média de 190 minutos por mês trafegados por usuário de telefonia móvel, de $100 \%$ de escolas públicas rurais com internet banda larga, sem especificação de capacidade de banda, de densidade de 32 assinaturas de televisão por assinatura por 100 domicílios no Brasil, de alcance de 42 milhões de domicílios com internet banda larga de qualidade por meio do Programa Nacional de Banda Larga (PNBL), de cobertura de $91,5 \%$ da população brasileira com serviço de telefonia móvel, de disponibilização de conexões de dados do SMP em alta e média capacidade, nas faixas de 1,9 / 2,1 GHz em pelo menos $75 \%$ dos distritosede de municípios do Brasil, de instalação de Telefone de Uso Público (TUP) em todos os postos de saúde públicos e escolas públicas, ambos em área rural, de oferta de banda larga fixa a 10 Mbps e móvel em redes 4G nas cidades-sede da Copa das Confederações de 2013, da Copa do Mundo de 2014 e dos Jogos Olímpicos de 2016, de pelo menos 2\% dos habitantes com acesso à internet banda larga em 95\% dos municípios; b) Objetivo 0752 Promover o uso de bens e serviços de comunicações, com ênfase nas aplicações, serviços e conteúdos digitais criativos para potencializar o desenvolvimento econômico e social do país, mediante alcance de $40 \%$ das populações das classes D e E fazendo uso da internet (acesso em banda larga e discado); c) Objetivo 0753 - Estimular a diversidade, a pluralidade e a competição entre meios e agentes da área das comunicações por meio da revisão do arcabouço regulatório e de ações que busquem oferecer o maior número possível de fontes de informação aos brasileiros, mediante alcance da meta de $100 \%$ de entidades radiodifusoras fiscalizadas em um intervalo de 4 anos, de $20 \%$ dos municípios com pelo menos uma emissora de radiodifusão outorgada com fins exclusivamente educativos, de 4,5\% dos municípios com pelo menos uma geradora de televisão outorgada, exceto aquelas com fins exclusivamente lucrativos, de $48 \%$ dos municípios com pelo menos uma emissora de radiodifusão sonora outorgada, exceto aquelas com fins exclusivamente educativos ou comunitários, de $51 \%$ dos municípios brasileiros com mais de uma emissora de radiodifusão outorgada, exceto rádio comunitária, de $60 \%$ dos municípios com pelo menos uma emissora de TV digital outorgada (geradora ou retransmissora), de $65 \%$ dos municípios com pelo menos uma emissora de televisão outorgada (geradora ou retransmissora); de $80 \%$ dos municípios com pelo menos uma rádio comunitária outorgada, de pelo menos um canal da Revista de Direito, Estado e Telecomunicações, v. 5, n. 1, p. 1-28 (2013) DOI: https://doi.org/10.26512/1str.v5i1.21561 
cidadania implantado em cada unidade da federação; d) Objetivo 0754 Promover o desenvolvimento da cadeia produtiva brasileira das comunicações e sua inserção internacional a partir do fomento à pesquisa, desenvolvimento, inovação e do estímulo ao uso de bens e serviços com tecnologia nacional, mediante, entre outros, a elevação para $70 \%$ a participação da produção nacional no mercado nacional de equipamentos e aparelhos de telecomunicação; e) Objetivo 0964 - Ampliar e fortalecer o Sistema Público de Comunicação e Radiodifusão, buscando universalizar o acesso da população à programação complementar e diversificada de natureza educativa, artística, cultural, informativa, científica e promotora da cidadania, mediante a ampliação da cobertura da TV Brasil Internacional a, pelo menos, 80 países, a ampliação da cobertura do sinal terrestre de radiodifusão, segundo a disponibilidade do Plano Básico de Outorgas, para garantir o acesso de, pelo menos, $50 \%$ da população brasileira à programação da TV Brasil, a ampliação da produção regional de conteúdos próprios da Empresa Brasil de Comunicação - EBC, implantando mais 3 canais geradores nas regiões Norte, Nordestes e Sul, para que a TV Brasil tenha ao menos uma geradora em cada região do país, e a ampliação para $100 \%$ da cobertura geográfica dos sinais de radiodifusão em Ondas Curtas (OC) e Ondas Tropicais (OT) da EBC para assegurar a recepção radiofônica a todas as localidades das Regiões Norte, Nordeste e Centro-Oeste não alcançadas por outras frequências.

Os números e percentuais projetam uma evolução em termos de expansão da infraestrutura como aposta governamental no sucesso dos incentivos à interconexão ou, ao menos, à conexão com a infraestrutura de backhaul público, mas a emergência das tensões institucionais podem ser o reflexo de duas causas principais e não excludentes: a expansão do alcance regulatório do setor de telecomunicações; a fragilização das instituições afirmadas há cerca de 14 anos atrás. Projeções de desenvolvimento que anunciam números para o setor sem serem acompanhadas de projetos de revisão institucional das tensões que caracterizaram o ano de 2012 podem estar apontando para o destino trágico de solução de tais tensões pela eliminação dos tensionados. 
